\title{
Presente e futuro dos estudos de Retórica, Argumentação e Discurso na América Latina*
}

\section{Entrevistada: María Alejandra Vitale}

Professora Titular regular da Universidade de Buenos Aires, Argentina orcid.org/0000-0002-2746-4070

\begin{abstract}
Nesta entrevista, exploramos a trajetória acadêmica de María Alejandra Vitale. Conversamos sobre sua carreira universitária e sua formação intelectual, sua participação em sociedades científicas de retórica, argumentação e discurso, bem como seus projetos de pesquisa na Universidade de Buenos Aires e na Agência Nacional de Promoção Cientíica e Tecnológica. Durante a interlocução, discutimos vários temas de importância social: a representação que a imprensa nacional fez das últimas ditaduras argentinas, o estudo dos chamados "arquivos da repressão", os discursos políticos e religiosos, com especial atenção à retórica da "nova" direita. Do olhar sobre essas questões, também faz parte uma reflexão teórico-metodológica sobre noções que a nossa entrevistada tem abordado com particular lucidez nas últimas décadas: a noção de memória retórico-argumentativa, a relação entre ethos e kairos, o diálogo interdisciplinar entre retórica, argumentação, análise do discurso e semiótica, entre outros.
\end{abstract}

Palavras-chave: Alejandra Vitale. Argentina. Retórica. Argumentação. Discurso.

\section{Presente y futuro de los estudios de Retórica, Argumentación y Discurso en América Latina}

En esta entrevista, exploramos la trayectoria académica de María Alejandra Vitale. Conversamos sobre su carrera universitaria y su formación intelectual, repasamos su participación en sociedades científicas de retórica, argumentación y discurso, y nos centramos en sus proyectos de investigación en la Universidad de Buenos Aires y en la Agencia Nacional de Promoción Científica y Tecnológica. Durante el intercambio, transitamos diversos temas de importancia social: la representación que la prensa nacional hizo de las últimas dictaduras argentinas, el estudio de los denominados "archivos de la represión", los discursos políticos y religiosos, con especial preocupación por la retórica de la "nueva" derecha. De la mirada sobre estos asuntos, es parte también una reflexión teórica-metodológica sobre nociones que nuestra entrevistada ha abordado con particular lucidez en las décadas recientes: la noción de memoria retórico-argumental, la relación entre ethos y kairos, el diálogo interdisciplinario entre retórica, argumentación, análisis del discurso y semiótica, entre otros.

Palabras clave: Alejandra Vitale. Argentina. Retórica. Argumentación. Discurso.

\section{Present and future of the studies of Rhetoric, Argumentation and Discourse in Latin America}

In this interview, we explore the academic career of María Alejandra Vitale. We talked about her professional background and her education, as well as her participation in scientific societies of Rhetoric, Argumentation, and Discourse. We focused on her research projects at the University of Buenos Aires and at the National Agency for Scientific and Technological Promotion. Throughout the dialogue, we discussed various topics of social importance: the national press' representations of the last Argentine dictatorships, the study of the so-called "repression archives", the political and religious discourses, with special concern for the rhetoric of the "new" right. A theoretical-methodological reflection on notions that our interviewee has approached with lucidity in recent decades is also part of the gaze on these matters of public relevance: the notion of rhetorical-argumentative memory, the relationship between ethos and kairos, the interdisciplinary dialogue between Rhetoric, Argumentation, Discourse Analysis and Semiotics, among others.

Keywords: Alejandra Vitale. Argentine. Rhetoric. Argumentation. Discourse.

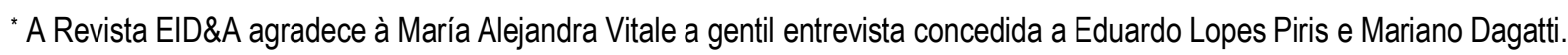


A EID\&A - Revista Eletrônica de Estudos Integrados em Discurso e Argumentação inaugurou em agosto de 2021 sua seção Entrevistas, tendo em vista o projeto de dar relevância à atuação de pesquisadoras e pesquisadores que contribuíram para a consolidação do campo de pesquisa da Retórica, Argumentação e Discurso, quer seja em nível nacional ou internacional.

Começamos nosso projeto entrevistando o professor e pesquisador português Rui Alexandre Grácio e, neste número, a Revista EID\&A oferece ao seu leitor uma entrevista com a professora e pesquisadora argentina María Alejandra Vitale, especialista em discursividade política, discursos golpistas na América do Sul e discursos dos serviços de inteligência secreta dos órgãos de censura, tendo publicado, pela Editora da Universidade de Buenos Aires (EUDEBA), em 2015, seu livro ¿Cómo pudo suceder? Prensa escrita y golpismo en la Argentina (1930-1976), além de inúmeros artigos em periódicos acadêmicos.

Nesta entrevista, exploramos a trajetória acadêmica de María Alejandra Vitale, começando por temas sobre sua formação e construção da sua carreira universitária, passando por sua contundente participação em sociedades científicas de Retórica, Argumentação e Discurso, até chegar aos seus projetos de pesquisa desenvolvidos na Universidade de Buenos Aires e na Agência Nacional de Promoção Científica e Tecnológica, a partir dos quais foram explicitadas temáticas socialmente importantes como a representação que a grande imprensa nacional fez das mais recentes ditaduras argentinas e o discurso da repressão ditatorial nos relatórios dos censores disponibilizados nos arquivos secretos dos órgãos policiais da Argentina que, os quais recentemente se tornaram públicos, bem como resultados teóricos importantes como a noção de memória retórico-argumentativa, a relação entre ethos e kairós, entre outros, contribuindo, fortemente, para os estudos da Retórica, Argumentação e Discurso da e na Argentina e América Latina.

Esperamos que desfrutem da leitura! 
EID\&A: Primeiramente, é um prazer poder entrevistar uma professora e pesquisadora tão atuante e importante para a Argentina e, também, para a América Latina. Muito obrigado por ter aceitado nosso convite! Alejandra, gostaríamos de começar falando sobre sua formação acadêmica, para além do que está em seu curriculum vitae. Você fez sua graduação e doutorado na Universidade de Buenos Aires, pesquisando sobre o discurso e a argumentação da imprensa argentina sobre os golpes de Estado durante o período 1930-1976. Quando, como e com quem foi seu primeiro contato com os estudos de retórica e/ou argumentação? O que se estudava na Argentina em termos de argumentação no período em que você era estudante?

Alejandra Vitale: Desenvolvi parte de meus estudos de graduação no curso de Letras na Faculdade de Filosofia e Letras da Universidade de Buenos Aires durante a última ditadura militar na Argentina (1976-1983). Por isso, foi censurada qualquer perspectiva que analisasse a linguagem em seus usos contextualizados e nos permitisse refletir sobre suas relações com a vida político-social. Os estudos clássicos, por sua vez, limitavam-se a ensinar uma gramática descontextualizada do grego e do latim. Consequentemente, o estudo da retórica e da argumentação foram excluídos da Universidade. Foi a partir de 1983, com a restauração da democracia e a (re)construção gradual do pluralismo, que a retórica e a argumentação foram paulatinamente ganhando espaço na sala de aula. Nos estudos clássicos, isso acontecia com a figura de dois professores notáveis, antes proibidos, que marcaram a era pós-ditadura: Ramón Alcalde, que reintroduziu temas de retórica nos cursos de grego antigo, e Eduardo Prieto, que tomou medida semelhante nos programas de latim. Nesse sentido, podemos afirmar que o caso da Argentina confirma o tema presente em Tácito, em seu Diálogo dos Oradores ${ }^{1}$, segundo o qual a retórica entra em decadência por falta de atividade política. Esse mesmo tema foi reformulado por Michel Meyer (2008), que argumenta, em seu livro Principia Rhetorica, que a Retórica renasce quando os dogmas se desintegram e por Marc Angenot (2008), que vincula o retorno triunfante da retórica à crise das Grandes Histórias e ao desencanto das religiões seculares ou políticas.

A democratização da Universidade de Buenos Aires a partir de 1983 implicou a modificação dos planos de estudos e a abertura de concursos públicos para preencher os cargos de professores. No curso de Letras e no Ciclo Básico Comum, o primeiro ano da Universidade de Buenos Aires, foram introduzidos conteúdos sobre análise do discurso e argumentação. No meu caso, meu contato com a área foi no âmbito de minha prática docente naquele primeiro ano na Universidade de Buenos Aires, quando publiquei, em colaboração com um colega da época, o livro La argumentación. Una aproximación retórico-discursiva (REALE; VITALE, 1995), elaborado principalmente, embora não exclusivamente, como uma bibliografia para os alunos e as alunas. Desde então aparecia meu interesse em vincular o estudo da argumentação ao da ideologia, especialmente em fazer a Nova Retórica de Perelman dialogar com noções de análise

\footnotetext{
1 TÁCITO. Diálogo dos oradores. Tradução: Antônio Martinez de Rezende e Júlia Batista Castilho de Avellar. Belo Horizonte: Autêntica, 2014.
} 
do discurso de orientação francesa, tais como o de formação discursiva. E o livro propõe algo semelhante para o estudo da organização do discurso argumentativo, ao conectar a perspectiva de Marc Angenot sobre o discurso entimemático aos estudos dos conectores argumentativos.

EID\&A: Considerando que as temáticas escolhidas para pesquisa dizem algo sobre o pesquisador, você poderia nos dizer quais foram as suas motivações para estudar os discursos sobre a ditadura argentina tanto no período em que você era estudante como na condição atual de líder do grupo de pesquisa GIAR $^{2}$ ?

Alejandra Vitale: Na época em que eu ia entrar no que é conhecido no Brasil como Ensino Médio, eu queria fazer o vestibular para o Colégio Nacional Buenos Aires, uma instituição de prestígio vinculada à Universidade de Buenos Aires. Minha família não me deixou, porque eram tempos de ditadura e eles temiam que eu me envolvesse na política e pudesse acabar desaparecendo. Na verdade, muitos estudantes do Colégio Nacional Buenos Aires desapareceram durante a última ditadura militar. Acabei frequentando um colégio de freiras, exclusivamente feminino. A atmosfera era horrível, retrógrada, repressiva e pró-ditatorial. As professoras argumentaram a favor do golpe militar que derrubou a presidente constitucional Isabel Perón e contra a chamada "subversão".

A aliança de setores da Igreja Católica argentina com as Forças Armadas e o ambiente de censura e repressão foi, portanto, um processo histórico que vivi no cotidiano da minha própria adolescência e que não esqueci mais. Acho que isso influenciou, consciente ou inconscientemente, muitos anos depois, a escolher como objeto de minha tese de doutorado a análise das estratégias argumentativas utilizadas pela imprensa escrita argentina para justificar os golpes de Estado e as práticas repressivas. De fato, em minha pesquisa de doutorado descobri que, em certos setores golpistas, um dos temas mais utilizados para justificar os golpes militares foi o que chamei, segundo 0 historiador Loris Zanatta ${ }^{3}$, de mito da nação católica. Este mito postula como critério de legitimidade de um governo não o mandato popular expresso no sufrágio, mas a busca do bem comum segundo a aplicação dos princípios da doutrina cristã. Dessa maneira, - mito da nação católica confunde as fronteiras entre Igreja e Estado e promove a instauração de um Estado católico, tarefa que a Igreja delega ao Exército, instituição que juntamente com a própria Igreja constituiria as bases da nacionalidade, das quais as Forças Armadas são guardiãs. Por sua vez, esse mito estabeleceu uma relação interdiscursiva com a Doutrina de Segurança Nacional, que concebeu a defesa do cristianismo como um freio contra o avanço do comunismo.

\footnotetext{
2 Grupo de Investigación en Archivos de la Represión: https://grupoinvestigacionarchivosdelarepresion.wordpress.com

3 ZANATTA, Loris. Perón y el mito de la nación católica. Iglesia y ejército en los orígenes del peronismo, 19431946. Sudamericana: Buenos Aires, 1999.
} 
Em relação à minha pesquisa sobre o discurso dos serviços de inteligência, lembro que o mestrado em História e Memória, ministrado na Universidade Nacional de La Plata, me convidou a dar uma conferência sobre as estratégias que a imprensa escrita argentina utilizou para argumentar a favor de golpes de Estado durante o período 19301976. A sala onde aconteceu a conferência está localizada na Comissão Provincial da Memória e, nessa ocasião, soube que tal Comissão era a responsável pela guarda do arquivo da Diretoria de Inteligência de Polícia da Província de Buenos Aires (DIPBA), serviço de inteligência policial instaurado em 1956 e encerrado em 1998. Percebi de imediato que não existiam pesquisas anteriores, em análise do discurso e na retórica, que tivessem estudado este tipo de arquivo, conhecido como arquivos da repressão. $E$ entendi também que estudá-los daria continuidade ao meu interesse em analisar discursos autoritários produzidos, em muitos casos, em conjunturas ditatoriais ou quase constitucionais, para os quais eu já dispunha de insumos consideráveis a partir de minhas pesquisas anteriores e de leituras provenientes da historiografia, da ciência política e da sociologia.

EID\&A: Como seus estudos atuais sobre arquivos de repressão e serviços de inteligência ${ }^{4}$ se relacionam com suas primeiras pesquisas? O que a análise desses arquivos aportou ou ainda pode vir a aportar aos estudos de Retórica, Argumentação e Discurso?

Alejandra Vitale: Um importante ponto de contato é a caracterização dos discursos e estratégias que legitimaram e foram condição para a possibilidade de práticas repressivas e autoritárias, e de regimes ditatoriais ou quase constitucionais. Trata-se de desmontar os mecanismos retóricos e argumentativos que tenderam a torná-los aceitáveis tanto na esfera pública por meio da imprensa escrita quanto no espaço secreto dos serviços de inteligência. Nesse sentido, penso que o discurso acadêmico também é construtor de memórias e intervém a seu modo nos debates sobre elas, razão pela qual as duas pesquisas, numa perspectiva interdisciplinar, são relevantes para o campo dos estudos de memória social (JELIN, 2002). Quanto às contribuições das pesquisas sobre os arquivos da repressão, elas enriqueceram a noção de comunidade discursiva de Maingueneau ao considerar os grupos de produtores desses arquivos como comunidades discursivas. Nesse sentido, o GIAR (Grupo de Investigación en Archivos de la Represión) constatou que um órgão de inteligência como a DIPBA, que tinha sede central na cidade de La Plata e delegacias em vários municípios da província de Buenos Aires, constrói diferentes cenografias enunciativas e relações com outros

\footnotetext{
${ }_{4}$ Projetos de pesquisa coordenados pela doutora María Alejandra Vitale e financiados por agências argentinas de fomento: (1) de 2020 a 2023: Memorias discursivas encontradas, ethos e antiethos em vigilantes e vigiados - 0 arquivo "Prefectura" da Diretoria de Inteligência da Polícia da Província de Buenos Aires e testemunhas do Arquivo oral da Comissão Provincial da Memória; (2) de 2017 a 2020: A comunidade discursiva do Arquivo da Diretoria de Inteligência da Polícia da Província de Buenos Aires; (3) de 2016 a 2018: Os arquivos da Diretoria Geral de Informações da Província de Santa Fé e da Diretoria de Inteligência da Polícia da Província de Buenos Aires - um estudo comparativo de duas comunidades discursivas.
} 
serviços de inteligência, por exemplo, a Secretaria de Inteligência do Estado (SIDE). Esses dados levaram a problematizar certa concepção homogeneizante e essencialista que emerge da noção de comunidade discursiva de D. Maingueneau. Ao mesmo tempo, pensei na heterogeneidade inerente às comunidades discursivas a partir das propostas de Jean-Luc Nancy ${ }^{5}$ e Roberto Esposito ${ }^{6}$ para propor a noção de relações intercomunitárias. Nesse sentido, pudemos argumentar que as comunidades discursivas não possuem uma identidade positiva ou característica essencial que as constitua, mas que, nas relações intercomunitárias, elas adquirem seus traços identitários, o que constitui um processo aberto em sua historicidade. As pesquisas também possibilitaram propor que as comunidades discursivas podem ser pensadas como comunidades afetivas, no sentido em que se regulam - por meio de normas, estereótipos e valores - emoções legítimas e ilegítimas, objetos ou pessoas aos quais podem ou não ser dirigidos e quais são os meios aceitáveis de expressá-los. Da mesma forma, assumo que as comunidades discursivas constituem comunidades argumentativas, que delimitam o campo do argumentável e são caracterizadas por certa lógica argumentativa e pela recorrência de certos esquemas persuasivos. Esses recursos argumentativos, usados, por exemplo, para fins de legitimação da censura e do controle cultural, estão muito bem explicados em um livro publicado em 2021 pela editora Santiago Arcos, de autoria de dois membros do GIAR que pude orientar em suas pesquisas de mestrado e, agora, em suas teses de doutorado, Paulina Bettendorff e Nicolás Chiavarino: Censura y control cultural en Argentina. Literatura, teatro, cine.

Ao estudar não apenas a dimensão verbal, mas também icônica e multimodal da discursividade dos arquivos da repressão, argumentei que uma comunidade discursiva é inerente a um certo regime escópico (JAY, 2003), um comportamento particular da percepção visual que implica um determinado verossímil a partir do visível. Nesse sentido e também em relação ao problema da memória discursiva, postulo que uma mesma matriz semiodiscursiva inerente a uma comunidade discursiva regula a memória tanto em sua dimensão verbal quanto visual. Compreendo por matriz semiodiscursiva as condições de possibilidade dos enunciados em materialidades significantes diversas; às regras geradoras da produção enunciativa de uma comunidade discursiva. Dessa maneira, refiro-me a uma memória verbo-visual que colabora com a coesão de uma comunidade discursiva e a legitimação de suas próprias práticas.

EID\&A: Em sua carreira, você dirigiu outros projetos de pesquisa além desses dois sobre os arquivos da repressão. Você poderia falar sobre as suas temáticas, motivações, hipóteses iniciais, dificuldades encontradas e principais resultados obtidos?

\footnotetext{
5 Ver: La comunidad inoperante (LOM/Arcis, 2000); La comunidad desobrada (Arena Libros, 2001); La comunidad descalificada (Avarigani, 2015); La comunidad revocada (Mardulce, 2016).

6 Ver: Communitas - Origen y destino de la comunidade (Amorrortu editores, 2003); Comunidad, inmunidad, biopolítica (Herder Editorial, 2009).
} 
Alejandra Vitale: Destaco o projeto de colaboração entre o Ministério da Ciência e Tecnologia da Argentina e a Fundação Nacional de Pesquisa da República da África do Sul, intitulado "Discursos fundacionais e identidades nacionais na Argentina e na África do Sul", codirigido com Philippe-Joseph Salazar, da Universidade da Cidade do Cabo. O projeto propôs uma investigação comparativa dos discursos fundacionais que estruturam a identidade nacional na Argentina e na África do Sul durante o período 1912-1994. No quadro da Retórica Crítica e retomando a análise do discurso, tivemos dois objetivos: identificar e caracterizar um amplo conjunto de discursos-chave que serviriam para o estudo dos princípios discursivos de duas sociedades políticas localizadas no Atlântico Sul e contribuir para os estudos internacionais sobre a chamada "retórica constitutiva" e a "retoricidade" da formação da identidade nacional. Nesse sentido, o projeto enriqueceu o campo dos estudos retóricos e do discurso na Argentina a partir do conhecimento e divulgação de uma linha de estudos retóricos até então ignorada na Argentina: a retórica constitutiva. O termo "retórica constitutiva" foi cunhado por James Boyd White (1985) com referência à capacidade da linguagem de criar a identidade coletiva de uma audiência. Foi retomado e divulgado pelo acadêmico canadense Maurice Charland (1986), que focaliza a noção de identificação como termo chave para a retórica. Essa noção permite repensar o efeito retórico ao rejeitar a ideia de um sujeito transcendental que ocuparia o lugar da audiência, que existiria antes independentemente do discurso. A ideia central da retórica constitutiva, segundo Charland, é que as audiências existem por meio do discurso, no sentido em que são construídas por ele, o que implica examinar como efeito retórico o que L. Althusser coloca como o processo-chave da ideologia: a constituição do sujeito. Charland analisa assim a construção retórica do povo quebequense, ao passo que nós, no grupo argentino do projeto, estudamos a construção retórica do povo argentino e consideramos como discursos fundadores aqueles proferidos por Juan Domingo Perón em 17 de outubro de 1945 e por Raúl Ricardo Alfonsín em 10 de dezembro de 1983. Estes são dois discursos que, cada um em seu contexto de produção e de diferentes modos, são centrais na constituição retórica da audiência com a identidade do povo argentino.

Por outro lado, o projeto abordou uma retórica das mulheres e uma retórica que denominamos "de baixo", já que a formação da identidade nacional também se baseia em formas retóricas muitas vezes autogeradas e não reguladas previamente. Nessa linha, foram estudados certos discursos de Eva Perón, como aquele que anuncia o voto feminino, que se afigura um discurso fundador, porque instaura, pela primeira vez, um novo destinatário: interpela politicamente a mulher e todas as mulheres. Eva Perón constrói uma consciência cívica, mas mantém a condição insubstituível que lhe corresponde a "coluna básica do lar", ou seja, o espaço simbólico gerado incorpora a mulher à cena política, mas sem perder de vista os valores espirituais nem os papéis tradicionalmente atribuídos ao gênero. O grupo argentino também considerou como discurso fundador o que Hebe de Bonafini proferiu na última Marcha da Resistência das 
Mães da Plaza de Mayo durante a ditadura militar, por ser constitutivo de um novo sujeito político na democracia.

Por último, o projeto se propôs a estudar um terceiro grupo de discursos que abarca um fenômeno fundamental para o imaginário e as identidades nacionais: o papel da Igreja. A retórica religiosa é uma característica duradoura dos imaginários nacionais da Argentina e da África do Sul, não como um fenômeno eclesiástico (pregação aos fiéis), mas como um agente convincente de engajamento social e político. Em ambas as sociedades, a retórica religiosa afeta muitos níveis da população e se articula a momentos críticos da história política. A pesquisa teve como foco especial a renovação teológica e sua incidência na deliberação pública, com o Movimento dos Sacerdotes para o Terceiro Mundo na Argentina e a figura de Monsenhor Tutu na África do Sul, de grande peso na luta contra o apartheid. No entanto, o Ministério da Ciência e Tecnologia da Argentina não depositou os recursos para a última etapa do projeto e este eixo ficou inacabado. Portanto, a maior dificuldade que este projeto tem enfrentado tem sido 0 financiamento.

EID\&A: Vamos mudar um pouco o tema de nossa conversa. Alejandra, além de ser participante ativa de sociedades científicas, você também foi presidenta e cofundadora de algumas delas, como a Associação Argentina de Retórica, a Associação Latinoamericana de Retórica e a Organização Ibero-americana de Retórica. Após estar à frente dessas associações, você poderia dizer quais foram as principais conquistas promovidas por essas sociedades científicas e quais seriam, a seu ver, os principais desafios a vencer nos próximos anos, para continuar impulsionando e promovendo os estudos de Retórica, Argumentação e Discurso na academia latino-americana.

Alejandra Vitale: As associações de retórica no âmbito latino-americano e iberoamericano têm difundido e consolidado os estudos retóricos na região, têm gerado e aprofundado laços acadêmicos entre as diversas universidades e têm fortalecido os vínculos com sociedades de retórica de outros espaços, incluindo Estados Unidos, Europa e China. Essas sociedades científicas têm estreitado o diálogo entre os especialistas em retórica e argumentação oriundos dos estudos da antiguidade grecoromana e de outras perspectivas, como a análise do discurso, a semiótica e a pragmática. Essa troca agrega novas e originais contribuições teórico-metodológicas aos textos antigos, bem como conhecimento e compreensão da retórica antiga para aqueles que se dedicam à retórica e discursividade contemporâneas. Da mesma forma, têm favorecido a formação de equipes de pesquisa interdisciplinares.

Outra conquista é a criação de revistas que ocupam um espaço antes vago, como a revista Rétor (www.revistaretor.org), da Associação Argentina de Retórica, a revista Metáfora. Revista de Literatura y Análisis del Discurso (www.metaforarevista.com), da Associação Peruana de Retórica, e a Revista Espanhola de Retórica, da Sociedade Espanhola de Retórica. Essas publicações eletrônicas permitem dar a conhecer e incentivar os conhecimentos produzidos, especialmente na América Latina, Espanha e 
Portugal, no campo da retórica e da argumentação, bem como ampliar as citações bibliográficas mútuas entre acadêmicos e acadêmicas do espaço latino-americano. Também foram estabelecidos e fortalecidos encontros científicas periódicos em vários países latino-americanos e promovidos novos cursos de pós-graduação, por exemplo, - Mestrado em Retórica e Argumentação, da Universidade Nacional de Tucumán, na Argentina, do qual sou codiretora.

Até o momento, existem associações de retórica na Argentina, Brasil, Chile, Colômbia, Bolívia, Peru, Cuba e México. Aspiramos que novas associações sejam criadas em outros países da região, bem como sejam abertos outros cursos de pós-graduação em Retórica e Argumentação. Já existe a rede de Retórica Jurídica coordenada pelo professor mexicano Gerardo Ramírez Vidal e esperamos que se abram novas redes com outras temáticas e problemáticas. Da mesma forma, incentivaremos as parcerias com diversos setores da sociedade, a exemplo da experiência iniciada no México com o sistema judicial.

EID\&A: No conjunto de sua obra (tese, livro, artigos e conferências), percebemos que seu empreendimento teórico busca articular a análise do discurso com a retórica e a argumentação, para, principalmente, elaborar a noção de memória retóricoargumentativa, a qual permite compreender a dimensão argumentativa da memória discursiva. Então, você poderia nos dizer quais foram ou ainda são os principais desafios de articular as teorias do discurso com as teorias da argumentação?

\section{Alejandra Vitale:}

Com efeito, para estudar a dimensão argumentativa das memórias discursivas, cunhei o termo "memória retórico-argumentativa" com referência ao retorno e reformulação, em uma série discursiva, de estratégias persuasivas que procuram adesão em torno de determinada tese. Essas estratégias persuasivas abrangem os tópicos, o ethos e a construção do passado, como explico em meu livro ¿Cómo pudo suceder? Prensa escrita y golpismo en Argentina (1930-1976). Posteriormente, argumentei que o pathos também faz parte da memória retórico-argumentativa (VITALE, 2020).

O termo "memória retórico-argumentativa" remete a uma perspectiva retórica do estudo da argumentação, que, quando articulada à perspectiva francesa da análise do discurso, precisa reformular a concepção de sujeito subjacente na retórica. Com efeito, o sujeito da retórica é semelhante ao da pragmática e, portanto, é um sujeito intencional, portador de escolhas e decisões, dono do sentido de seus enunciados; um sujeito que conscientemente desenvolve estratégias para atingir um determinado propósito. Sabese que para Pêcheux esse sujeito é uma ilusão que se encontra no que ele chama de "forma-sujeito". O espaço de constituição da subjetividade é, no entanto, inacessível ao sujeito e está ligado ao inconsciente e à ideologia, que - como aponta L. Althusser (1996 [1970]) - constitui os indivíduos em sujeito por meio da interpelação. 
Tanto a tradição retórica quanto a Nova Retórica de Ch. Perelman são alheias ao materialismo histórico e à psicanálise, fundamentais para a teoria do discurso de Pêcheux. No caso de Perelman, sua teoria se constitui no quadro do liberalismo político que valoriza o pluralismo como marco indispensável para a convivência pacífica entre quem pensa diferente. Desse modo, a noção de luta de classes, central na proposta de Pêcheux, se contrapõe à ideia de razoabilidade de Perelman, cujo horizonte é o consenso. Mas, embora Perelman admita a relatividade, a pluralidade da razoabilidade não se estende a uma perspectiva da sociedade na qual as relações de poder, a divergência de interesses e as profundas diferenças ideológicas fazem do conflito e do agon o motor da democracia.

Considerando essas diferenças marcantes, argumentei que as memórias retóricoargumentativas são próprias a determinadas posições ideológicas que delimitam as posições do sujeito. Os sujeitos enunciadores, ao se identificarem com essas posições de sujeito, produzem, na atualidade de um acontecimento discursivo, as estratégias retóricas que integram as memórias retórico-argumentativas. Dessa maneira, a defesa ou a rejeição a certas teses e os meios para justificá-las ou refutá-las, as estratégias persuasivas que retornam e se reformulam em uma série discursiva, de média ou longa duração, são próprias a determinadas posições ideológicas e a posições de subjetividade que elas configuram.

As memórias retórico-argumentativas são, portanto, matrizes de produção de estratégias retóricas e de sentidos que determinam tanto o que pode ou não pode ser dito quanto os modos de dizê-lo, para um sujeito que não é totalmente senhor de seu dizer, uma vez que ele se estabelece como tal ao se identificar com uma posição de subjetividade delimitada por uma ideologia à qual é inerente uma memória retóricoargumentativa. A ideologia é pensada aqui como as relações que todo discurso estabelece com suas condições materiais de possibilidade, nas quais as lutas pelo estabelecimento e reprodução das relações de poder, ou resistência a elas, ocupam um lugar central. Por isso, as memórias retórico-argumentativas não são espaços fechados, estáveis ou homogêneos, mas apresentam fronteiras difusas e instáveis caracterizadas por laços de aliança ou contradição.

EID\&A: E quais são os ganhos que uma pesquisa pode obter, em termos de análise, ao convocar a noção de memória retórico-argumental?

Alejandra Vitale: Em primeiro lugar, a noção de memória retórico-argumentativa permite analisar o funcionamento da memória discursiva em termos argumentativos, compreender que o retorno do já dito e dos modos de dizer do passado numa nova conjuntura têm a função de gerar ou aumentar a adesão a uma determinada tese. É importante considerar o discurso em sua historicidade, pois ao se analisar essa dimensão argumentativa das memórias discursivas é necessário contemplar as mutações do sentido e das próprias estratégias, que se situam tanto no nível do enunciado quanto no da enunciação. Essas mutações são causadas pela incidência das 
várias conjunturas históricas em que a memória retórico-argumentativa retorna. Por isso, a noção de memória retórico-argumentativa permite investigar a incidência na palavra argumentativa não apenas no curto tempo do acontecimento, mas, como fez a Escola dos Annales em sua época, na longa duração, ou, pelo menos, num tempo médio que exceda a evanescência. A esse respeito, gosto de parafrasear uma frase de Marx do $18^{\circ}$ Brumário para afirmar que o discurso e os argumentos de todas as gerações mortas oprimem os cérebros dos vivos como um pesadelo.

Por outro lado, a noção de memória retórico-argumentativa permite explicar o parentesco argumentativo entre os discursos de diferentes países diante de acontecimentos históricos semelhantes ou subsumidos a processos que os englobam. É que estudei de forma comparativa com os discursos golpistas da Argentina, Brasil e Uruguai. Como explicar a semelhança familiar entre os discursos golpistas de 1964 no Brasil, os de 1973 no Uruguai e os da Argentina em 1966 e 1976, e todos estes com os discursos golpistas anteriores deste país no período 1930-1976? A noção de memória retórico-argumentativa contribui para essa explicação.

Por fim, as memórias retórico-argumentativas permitem analisar a heterogeneidade constitutiva característica de toda a palavra persuasiva, na qual o já dito é retomado, enquanto reformulado, em uma nova conjuntura, para persuadir um determinado auditório.

EID\&A: Seus trabalhos também têm mobilizado a noção de ethos. Considerando o boom que essa noção conheceu desde 1987 com os trabalhos de Maingueneau, em que medida a noção de ethos não tende a se concentrar no subjetivo e perder de vista uma dimensão estrutural e crítica do ideológico? Ademais, você entende que os estudos sobre ethos já estão saturados ou ainda existem perguntas que devem ser respondidas? Se assim for, o que mais pode ser pesquisado a respeito do ethos?

Alejandra Vitale: Penso que o estudo do ethos não leva necessariamente a perder de vista uma dimensão estrutural e crítica do ideológico. Em suas primeiras reflexões sobre o ethos, Maingueneau (1987) o considera uma das dimensões das formações discursivas e, portanto, articulado à ideologia. Em minhas próprias propostas sobre 0 ethos como estratégia persuasiva integrante da memória retórico-argumentativa, também o vinculei à ideologia e ao eixo do interdiscurso. Nessa mesma linha, argumentei (VITALE, 2018) que todo ethos está atravessado tanto pelo kairós quanto por uma posição de subjetividade delimitada por uma formação discursiva. Para a retórica, o kairós é a articulação dos objetivos do orador com o tempo, o lugar e as circunstâncias do auditório a que se dirige, num processo que tem como finalidade a produção de um discurso conveniente (prepô), que combine com harmonia a forma e o conteúdo. O kairós está assim ligado à singularidade de uma situação retórica específica, ao aqui e agora de uma enunciação, que a partir da análise do discurso pode ser pensada com a noção de acontecimento discursivo. Ao mesmo tempo, todo ethos constitui uma das dimensões de uma formação discursiva, implica um sujeito de saber 
como posição de subjetividade, que se vincula à noção de estrutura e interdiscurso e ao eixo da repetição, da regularidade. Ilustrei essa proposta com discursos da expresidente argentina Cristina Fernández de Kirchner, nos quais identificamos, por um lado, um ethos pedagógico e experiente, vinculado ao kairós e ao aqui e agora da enunciação, pois se relaciona com o fato de que ela é a primeira mulher presidente eleita que deve construir uma identidade que a associe e a diferencie de seu marido e expresidente Néstor Kirchner e, por outro lado, observamos um ethos guerreiro e antiinstitucionalista, interdiscursivamente vinculado a uma formação discursiva própria de uma ideologia populista.

Em relação aos novos questionamentos e pesquisas sobre o ethos, o ethos coletivo e sua construção é uma linha que ainda pode dar resultados interessantes, principalmente no que se pode chamar de ethos digital coletivo, utilizando o termo cunhado por Laura Bonilla Neira, em sua tese de doutorado orientada por mim. Com efeito, examinar como as redes sociais incidem sobre a conformação de grupos e suas respectivas identidades é uma tarefa frutífera. Também é importante aprofundar a investigação sobre o que tem sido chamado de ethos feminino, particularmente na discursividade política. Nas pesquisas do GIAR sobre os arquivos da repressão, investigamos a identidade discursiva dos agentes de inteligência, tal como constará no próximo livro que preparei para a editora EUDEBA: Rutinas del mal. Estudios discursivos sobre archivos de la represión. Seria interessante realizar estudos contrastivos com a conformação do ethos de agentes de inteligência de outros países sul-americanos em arquivos da repressão que também estão abertos para consulta pública.

EID\&A: Pensando numa interface com a Semiologia, você poderia nos dizer algo sobre como abordar as múltiplas dimensões do sentido (o colocar-se em cena, o corporal, o visual), a partir de uma perspectiva argumentativa e/ou retórica?

Alejandra Vitale: Em primeiro lugar, destaco a atualidade da tradição retórica. Sabe-se que os gestos e a entonação que acompanham a manifestação pública do discurso foram estudados pelo que a antiga retórica chamava de Actio. Aristóteles, em sua Retórica, dedicou muito pouco espaço a isso na primeira parte do Livro III e focalizou a voz em detrimento dos gestos. Por sua vez, em seu De Oratore, Cícero pondera que a Actio é uma parte fundamental da Retórica, oferecendo-lhe um segmento mais extenso do que Aristóteles, porém ainda prestando mais atenção à voz do que ao gesto. A Actio ganha muito mais destaque na Instituição Oratória de Quintiliano, sendo referida em um capítulo inteiro do Livro $\mathrm{XI}^{7}$. Porém, em Quintiliano, a voz também tem primazia sobre o gesto, dado que anuncia que irá se dedicar antes à voz que ao gesto, porque todo afeto penetra na alma pelos ouvidos e o gesto se acomoda à voz. Nos três autores, a voz é assim considerada sobre o gesto e, igualmente, a Actio está vinculada às paixões. Isso envolve o pathos, as emoções despertadas no auditório, mas também o ethos, na

\footnotetext{
7 QUINTILIANO, Marcos Fábio. Instituição Oratória. Tradução: Bruno Fregni Bassetto. Campinas: ED.UNICAMP, 2016. Tomo IV.
} 
medida que a voz e o gesto expressam as emoções experimentadas ou simuladas pelo orador.

No meu caso, tenho me interessado pela força retórica de um gesto semiótico muito denso, o riso/sorriso, e especificamente no discurso político presidencial de Cristina Fernández de Kirchner (VITALE, 2014). O sorriso que acompanha um enunciado verbal tem as características que G. Calbris (2003) atribui aos gestos coverbais: são signos eminentemente contextuais, convencionais, motivados e polissêmicos, que cumprem as mesmas funções comunicativas dos signos verbais. No campo da retórica, Maria Silvana Celentano (1995) diferencia o riso/sorriso alheio à agressão e às relações hierárquicas (como alegria, acolhimento etc.) e o riso/sorriso que envolve agressão e hierarquia (como zombaria, desprezo, vitória etc.) e que geralmente supõe um próximo e/ou um terceiro que é objeto de riso/sorriso. No quadro da análise do discurso, Marion Sandré (2011) distingue entre o riso/sorriso com efeito de consenso e o riso/sorriso com efeito de dissenso. Por outro lado, aborda o riso/sorriso na medida que produz um efeito capaz de intervir na interpretação do discurso: trata-se de um efeito atenuante ou, pelo contrário, um efeito amplificador e um efeito revelador de um determinado sentimento. No caso do sorriso de Cristina Fernández de Kirchner, aparecem os dois tipos de sorriso. Por um lado, um sorriso não agressivo que acompanha a informalidade das suas alocuções ou a quebra do protocolo e cujo único destinatário é um próximo. Por outro lado, é um sorriso debochado com uma cota de agressão que inclui não só o próximo como também o terceiro que provoca o sorriso, o antagonista político, com quem a presidenta argentina polemiza. Em ambos os casos, pode-se afirmar que 0 sorriso tem um efeito amplificador, seja de informalidade, seja de polemicidade do dito.

Quanto ao estudo da argumentação em materialidades significantes diversas, essa questão nos remete ao campo da discussão sobre a argumentação multimodal, que tem muito peso nas mídias digitais e nas redes sociais. As imagens visuais foram enfatizadas e alguns lhes negaram a possibilidade de argumentar, alegando que são ambíguas e vagas, que não podem ser reduzidas a proposições e apelam mais às emoções do que à razão. No entanto, três perspectivas importantes consideraram a análise da argumentação multimodal. A pragmadialética interessou-se por ela, por exemplo, em anúncios, cartazes, filmes e desenhos animados. Nesse sentido, Leo Groarke (1970) defendeu a posição de que as imagens argumentam, sustentando que uma imagem que expressa um ponto de vista com premissas de apoio é uma imagem argumentativa. Na perspectiva retórica, J. Anthony Blair (2004) sustenta que há argumentação visual se o que é comunicado inclui um fator que pode ser considerado como razão para aceitar uma proposição, mudar de atitude ou realizar uma ação. Isso pode ser observado, se se traduz verbalmente o que é comunicado visualmente. A argumentação visual, porém, em comparação com a argumentação verbal, é caracterizada pela falta de sutileza e pela simplicidade e impossibilidade de entrar em refutações e contra-argumentações. Por fim, a Análise Crítica do Discurso considera que os signos que se manifestam de diferentes formas - os recursos semióticos que ocorrem simultaneamente nos discursos, como a imagem visual, a posição espacial, o 
som, entre outros - são selecionados e organizados de acordo com os interesses, a partir dos quais os signos são produzidos. Nesse sentido, postula-se que os signos são motivados em sua relação entre forma e significado. A argumentação é concebida como persuasão e os estudos se concentram na leitura crítica de mensagens multimodais que discriminam as minorias ou legitimam relações desiguais de poder.

O campo da argumentação multimodal é hoje muito rico e em permanente reconfiguração, como demonstra no Brasil o recente número especial da Revista da ABRALIN (n. 20, v. 3, 2021).

EID\&A: Olhando para o contexto da academia latino-americana, que agenda de pesquisa você acredita que deveria ser priorizada para o desenvolvimento futuro dos estudos de Retórica, Argumentação e Discurso aqui na periferia do capital.

\section{Alejandra Vitale:}

Um problema que me parece importante é o estudo do entrelaçamento do discurso religioso e do discurso político a partir de uma perspectiva crítica, porque isso está vinculado à importância das lgrejas nas sociedades latino-americanas e seu alcance nos setores da população com direitos violados. Também é importante priorizar a análise do discurso da direita, em muitos casos relacionado ao das lgrejas, dado o avanço que tiveram no espaço eleitoral de muitos de nossos países. Compreender e desmontar suas lógicas retórico-argumentativas poderá contribuir para neutralizá-las e refutá-las no espaço público de forma mais eficaz. Algo semelhante acontece com os chamados discursos de ódio, aqueles que promovem ou legitimam a discriminação e/ou violência contra uma pessoa ou um coletivo em função de sua pertença a um grupo religioso, étnico, nacional, político, racial, de gênero ou qualquer outra identidade. Ao mesmo tempo, considero que, como as tramas discursivas do presente em nossos países se entrelaçam nas tramas da memória, é oportuno continuar pesquisar as memórias das ditaduras sul-americanas e suas funções em discursividades atuais. Em relação a essa agenda, penso que a perspectiva contrastiva entre os países sulamericanos contribuirá tanto para a integração acadêmica e política quanto para o compromisso com sociedades mais equitativas e menos violentas.

\section{Referências}

ALTHUSSER, Louis. Ideologia e aparelhos ideológicos de estado (notas para uma investigação). [1970]. In: ZIZEK, Slavoj (org.). Um mapa da ideologia. Tradução: Vera Ribeiro. Contraponto: Rio de Janeiro, 1996. p. 105-142.

ANGENOT, Marc. Dialogues de sourds. Traité de rhétorique antilogique. Paris: Mille et une Nuits, 2008 
BLAIR, John Anthony. The Rhetoric of Visual Arguments. In: HILL, Charles; HELMERS, Marguerite (eds). Defining Visual Rhetorics. Mahwah: Lawrence Erlabaum, 2004. p. 4161.

CALBRIS, Geneviève. L'expression gestuelle de la pensée d'un homme politique. Paris, CNRS Éditions, 2003.

CELENTANO, Maria Silvana. Comicità, umorismo e arte oratoria nella teoria retorica antica. Eikasmos. Quaderni Bolognesi di Filologia Classica, VI, p. 162-174, 1995.

CHARLAND, Maurice. Constitutive Rhetoric. Quarterly Journal of Speech, n. 73, v. 2, p. 133-150, 1986.

GROARKE, Leo. Toward a Pragma-Dialectics of Visual Argument. In: Van EEMEREN, Frans H. (ed.). Advances in Pragma-Dialectics. Amsterdam: Sic Sat, 2002. p. 137-151.

JAY, Martin. Regímenes escópicos de la modernidade. In: Campos de fuerza.

Entre la historia intelectual y la crítica cultural. Buenos Aires: Paidos, 2003.

JELIN, Elizabeth. Los trabajos de la memoria. Buenos Aires: Siglo XXI, 2002.

MAINGUENEAU, Dominique. Nouvelles tendance en analyse du discours. Paris: Hachette, 1987.

MEYER, Michel. Principia Rhetorica. Une théorie générale de l'argumentation. Paris: Fayard, 2008.

REALE, Analía; VITALE, Alejandra. La argumentación. Una aproximación retóricodiscursiva. Buenos Aires: Ars, 1995.

SANDRÉ, Marion. Mimiques et politique. Analyse des rires et sourires dans le débat télévisé. Mots. Les langages du politique, n. 96, p. 13-27, 2011

VITALE, María Alejandra. El ethos en la 'conversacionalización' del discurso público. Las alocuciones de asunción de la presidente argentina Cristina Fernández de Kirchner. Langage et Societé, Paris, n. 149, p. 49-67, 2014.

VITALE, María Alejandra. El èthos: entre el kairós y las formaciones discursivas. Estudios del Discurso, Cuernavaca, n. 4, v. 1, p. 36-50, 2018.

VITALE, María Alejandra. Memoria retórico-argumental y pathos. Revista Verbum, São Paulo, n. 9, v. 1, p. 254-268, 2020.

VITALE, María Alejandra. Memória retórico-argumentativa: encontro entre Perelman e Pêcheux. Tradução: Juan Facundo Sarmiento e Eduardo Lopes Piris. Linha D’Água, São Paulo, v. 29, n. 2, p. 156-172, 2016. DOI: 10.11606/issn.2236-4242.v29i2p156-172.

WHITE, James Boyd. Heracles' Bow. Madison: University of Wisconsin, 1985. 